\title{
Mechanical and Reaction Properties of PTFE/AI/MnO Reactive Materials at Different Strain Rates
}

\author{
Junyi Huang, Xiang Fang, Yuchun Li ${ }^{*}$, Jiaxiang Wu, Jiaxing Song \\ Institute of Battlefield Engineering, Army Engineering University, Nanjing, China \\ Email address: \\ huangjunyi357@163.com (Junyi Huang), fangxiang3579@163.com (Xiang Fang), liyuchunmai@sina.com (Yuchun Li), \\ 1263439505@qq.com (Jiaxiang Wu),674670871@qq.com (Jiaxing Song) \\ ${ }^{*}$ Corresponding author
}

\section{To cite this article:}

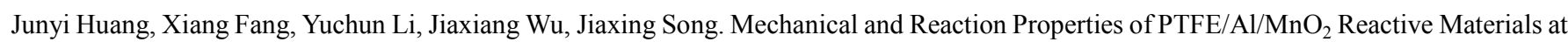
Different Strain Rates. Advances in Materials. Vol. 7, No. 2, 2018, pp. 50-57. doi: 10.11648/j.am.20180702.16

Received: June 28, 2018; Accepted: July 31, 2018; Published: August 13, 2018

\begin{abstract}
The mechanical responses of the $\mathrm{PTFE} / \mathrm{Al} / \mathrm{MnO}_{2}$ reactive material in the strain rate range of $10^{-3} \sim 4 \times 10^{3} \mathrm{~s}^{-1}$ were studied by a universal testing machine and split Hopkinson pressure bar (SHPB) system, and the microstructure of $\mathrm{PTFE} / \mathrm{Al} / \mathrm{MnO}_{2}$ specimen was observed by Scanning Electron Microscope (SEM). Meanwhile, a standard drop-weight apparatus was used to reveal the reaction properties and impact sensitivity of the $\mathrm{PTFE} / \mathrm{Al} / \mathrm{MnO}_{2}$ reactive material. The results demonstrate that under quasi-static compression conditions, the yield strength and compressive strength of $\mathrm{PTFE} / \mathrm{Al} / \mathrm{MnO}{ }_{2}$ specimens have obvious strain rate effects, while the elastic modulus and failure strain are insensitive to strain rate and remain almost unchanged. Under dynamic load conditions, the compressive strength of the PTFE/Al/ $\mathrm{MnO}_{2}$ specimen has a linear relationship with the logarithm of the strain rate, while the critical strain and the logarithm of the strain rate show a parabolic relationship. The established constitutive equation can describe the mechanical behavior of $\mathrm{PTFE} / \mathrm{Al} / \mathrm{MnO} \mathrm{material}_{2}$ at high strain rate well, which can provide a reference to the practical applications of the material. PAM specimens can react violently under the impact of a drop hammer, with intense light and a huge explosion sound. And the characteristic drop height of the PAM specimen was calculated as $58.13 \mathrm{~cm}$.
\end{abstract}

Keywords: PTFE, Mechanical Responses, Split Hopkinson Pressure Bar (SHPB), Dynamic Performance, Constitutive Equation, Impact Sensitivity

\section{Introduction}

Polytetrafluoroethylene (PTFE), which has good self-lubricity, chemical stability and low friction coefficient, is an excellent engineering plastic and an ideal anti-friction material, so it is typically used as a matrix for polymer composites. On the basis of PTFE, various granular reinforcing fillers are added, such as $\mathrm{Al}_{2} \mathrm{O}_{3}, \mathrm{SiC}, \mathrm{SiO}_{2}, \mathrm{Cu}_{2} \mathrm{O}$, $\mathrm{PbO}, \mathrm{Pb}_{3} \mathrm{O}_{4}, \mathrm{Cu}, \mathrm{Al}, \mathrm{W}$ [1-8], to prepare PTFE-based composites. These fillers not only enhance the density, strength, and hardness of PTFE-based composites, but also some of them, such as $\mathrm{Al}$ and $\mathrm{Mg}$, can react with PTFE [9-10], making PTFE-based composite materials more widely used in military and civilian applications.

The PTFE-based composite material is a typical polymer-based composite material, and its mechanical properties and failure modes under quasi-static conditions can be investigated by a universal testing machine. However, in some applications, such as warhead shells and shaped charge, the characterization and modeling of high strain rate responses of materials are necessary for structural design and analysis. Numerous researchers have experimentally reviewed and considered the effect of strain rate on polymer composites. Wang [3], Oguni [11], Feng [12] and Oguni [13] conducted high strain rate tests on polymer-based composites, showing that the compressive strength of polymer composites is sensitive to strain rate. Hsiao et al. [14-15] considered the effect of strain rate on the mechanical behavior of thick composites and found that the stress-strain curve has a significant strain rate effect. Of all the PTFE-based 
composites, PTFE/Al materials have received extensive attention in the past few years due to their easiness to deform and higher strength, stability, and energy density compared with traditional explosive [16]. Generally, the PTFE/Al is thought to be inert under quasi-static or static loads, but Feng et al. [17] revealed that the PTFE/Al composites with a mass ratio of 74:26 can react violently under quasi-static compression, which was prepared through a process of cold isostatic pressing (CIPing) and sintering. And a crack-induced initiation mechanism was proposed by Feng et al. [18]. In addition, this group also studied the effect of PTFE crystallinity on on the mechanical and reactive behavior of $\mathrm{PTFE} / \mathrm{Al}$ at strain rates range from $10^{-2}$ to $3 \times 10^{3} \mathrm{~s}^{-1}$ through quasi-static compression and split Hopkinson pressure bar experiments [19], which provide a good reference for us to understand the properties of PTFE/Al. In order to enhance the density of PTFE/Al composites, tungsten (W) was added to PTFE/Al and many scholars have carried out in-depth studies to understand the mechanical properties, failure modes and reaction characteristics of the W-reinforced PTFE/Al materials [20-24]. However, some researchers have been trying to add oxides based on PTFE/Al to increase the strength and energy density of materials recently. For example, quasi-static compression and drop-weight tests were used to characterize the mechanical and reaction behavior of $\mathrm{PTFE} / \mathrm{Al} / \mathrm{Fe}_{2} \mathrm{O}_{3}$ composites by Huang and Tao [25-26], and a High Temperature Metal Slag Spray (HTMSS) phenomenon was observed.

In order to ensure the stability and safety of the reactive materials in the process of manufacturing, transportation, storage, and the reliability during applications, it is necessary to understand the mechanical response and reaction performance of the reactive materials under different loading conditions. Split Hopkinson pressure bar (SHPB) technology is a commonly used technique for studying the mechanical response of materials at higher strain rates $\left(10^{2} \sim 10^{4} / \mathrm{s}\right)$. The initial model was proposed by Hopkinson in 1914 [27], and later improved by Kolsky [28]. In this study, a kind of $\mathrm{PTFE} / \mathrm{Al} / \mathrm{MnO}_{2}$ (PAM) particle-reinforced polymer composite was prepared by cold-pressing and sintering technology. The microstructure of this material was observed by scanning electron microscopy (SEM). The universal testing machine, split Hopkinson pressure bar (SHPB) device and a standard drop-weight apparatus were utilized to investigate the mechanical response and impact sensitivity at low strain rate and high strain rate, respectively. In addition, a constitutive equation based on the Johnson-cook (JC) plasticity model was established.

\section{Experimental}

\subsection{Sample Preparation}

The volume ratio of PTFE, $\mathrm{Al}$, and $\mathrm{MnO}_{2}$ was 60:18:22. The raw materials have the following average particle size:
PTFE: $25 \mu \mathrm{m}$ (3M, Shanghai); Al:1 $\mu \mathrm{m}$ (NAIO, Shanghai); $\mathrm{MnO}_{2}: 1-3 \mu \mathrm{m}$ (NAIO, Shanghai). The particle diameter was provided by the manufacturer.

The PAM specimens were prepared through a process including mixing, cold-pressing and sintering. $\mathrm{Al}, \mathrm{MnO} 2$ and PTFE powders were suspended in an ethanol solution and mixed by a motor-driven blender for $20 \mathrm{~min}$, then dried at $50^{\circ} \mathrm{C}$ for $48 \mathrm{~h}$ and cold pressed into cylinder samples under $60 \mathrm{MPa}$. The cylinders have sizes of $\phi 10 \mathrm{~mm} \times 10 \mathrm{~mm}$ and $\phi 10 \mathrm{~mm} \times 5 \mathrm{~mm}$, as shown in Figure 1, which were used for quasi-static compression tests and SHPB tests, respectively. Then the specimens were sintered at $360^{\circ} \mathrm{C}$ in a vacuum tube furnace with a cooling rate of $50^{\circ} \mathrm{C} / \mathrm{h}$.

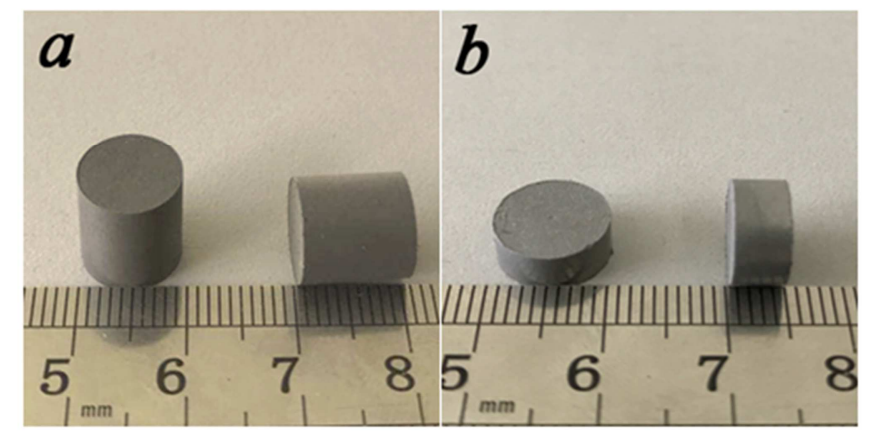

(a) used for quasi-static compression tests; (b) used for SHPB tests

Figure 1. PAM samples.

\subsection{Methods}

\subsubsection{Mesoscale Characteristics}

The microstructure of the specimen was observed using a Hitachi S-4800 field emission electron microscope (FE-SEM).

\subsubsection{Quasi-Static Compression Tests}

According to GB/T7314-2005, the CMT5105 microcomputer-controlled universal testing machine was used to perform quasi-static compression experiments on the sintered specimens to obtain the stress-strain curves of the material and the deformation and failure process of the specimen were analyzed.

\subsubsection{SHPB Tests}

In the SHPB tests, the length of the striker bar, incident bar and transmitted bar is $600 \mathrm{~mm}, 6000 \mathrm{~mm}$ and $3500 \mathrm{~mm}$ respectively, all of which are made of aluminum with a diameter of $20 \mathrm{~mm}$. The voltage signals in the incident and transmitted bars were recorded using a semiconductor strain gauge. In order to make the specimens reach the state of stress equilibrium and constant strain rate loading as soon as possible, a self-made rubber shaping sheet was attached to the incident end of the incident bar, with a thickness of $1 \mathrm{~mm}$ and a diameter of $10 \mathrm{~mm}$. The schematic diagram of SHPB device is illustrated in figure 2 . 


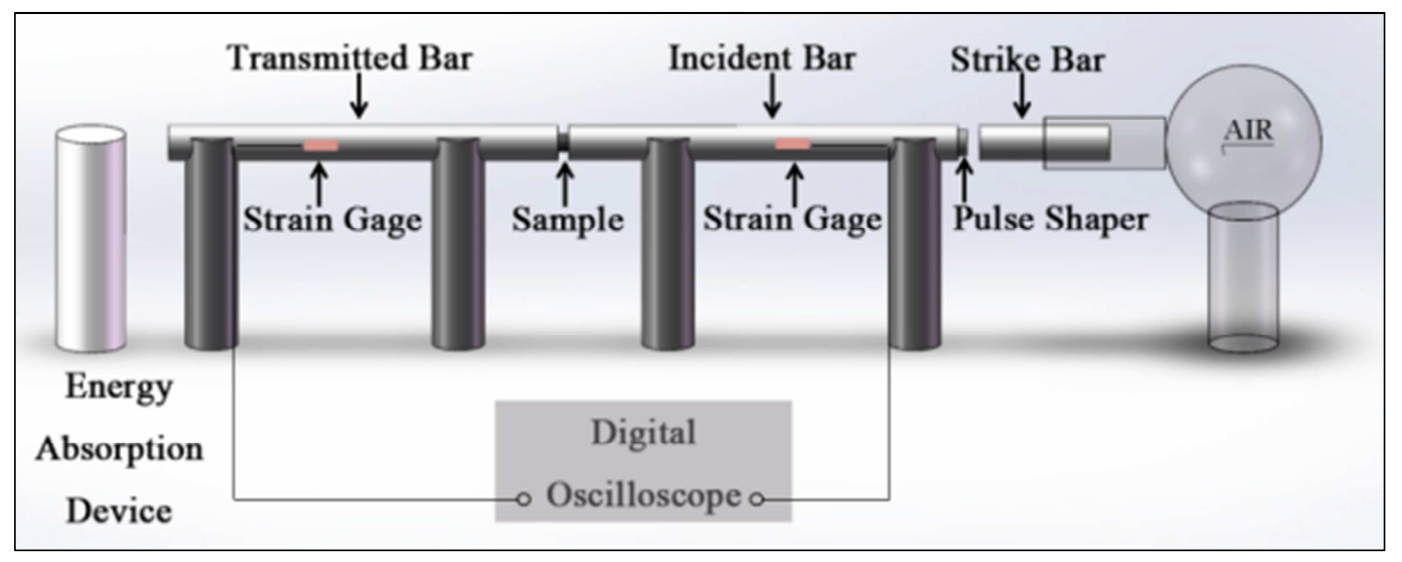

Figure 2. Schematic illustration of SHPB setup.

\subsubsection{Drop-Weight Tests}

The impact sensitivity of the PTFE/Al/ $\mathrm{MnO}_{2}$ material was investigated using a standard drop-weight apparatus in conjunction with a high-speed camera, and the schematic illustration is presented in Figure 3. The apparatus consists of a stainless steel plate (mass ca. $10 \mathrm{~kg}$ ) which can be released from a height of $150 \mathrm{~cm}$. When the drop mass was released, the high-speed camera was used to record the deformation process and reaction phenomenon of the specimen, and to determine whether the specimen was ignited based on the recorded images according to the "up-and-down technique" [29]. Once the suitable range of positive and negative reactions was found, the tests were performed at $2 \mathrm{~cm}$ intervals.

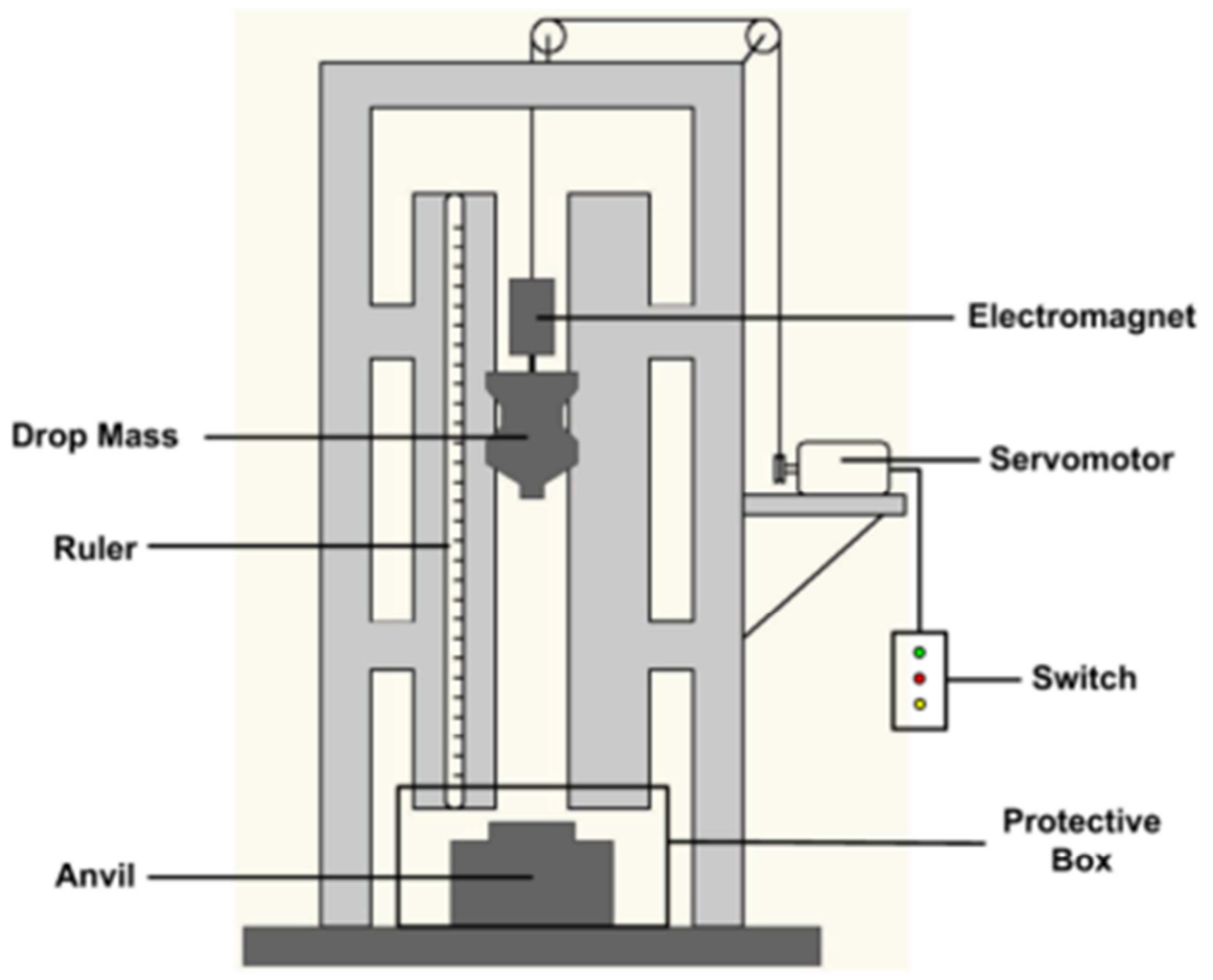

Figure 3. Drop-weight apparatus.

The test specimens were all painted with petroleum jelly to reduce friction, and the test temperature was $25^{\circ} \mathrm{C}$ in this study.

\section{Results and Discussion}

\subsection{Characterization of Materials}

The microstructure of the PAM specimen is shown in
Figure 4. As can be seen from Figure 4, Al particle is a relatively uniform sphere with a diameter of about $1.5 \mu \mathrm{m}$. And $\mathrm{MnO}_{2}$ is an irregular block with a diameter of about $2 \mu \mathrm{m}$. Al and $\mathrm{MnO}_{2}$ particles are "embedded" in the PTFE matrix, forming a composite interface between the particles and the matrix. PAM material is a typical particle-reinforced composite material, and its mechanical properties depend on 
the matrix and matrix/particle interface. In the sintering process of PAM, PTFE melts, expands and flows by heat, enveloping $\mathrm{Al}$ and $\mathrm{MnO}_{2}$ particles in the matrix and making such interface more tightly bound. The high-strength interface can effectively transfer the load from the matrix to the particles, and can also deflect the propagation direction of cracks in the matrix or prevent the development of cracks, so the material has strong mechanical properties.

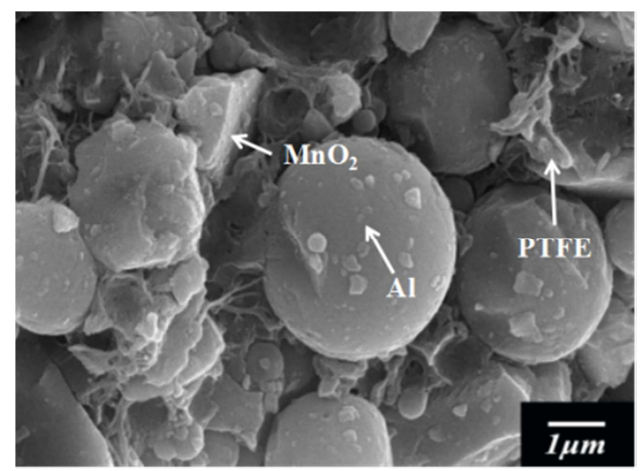

Figure 4. Microstructureof PAM specimen.

\subsection{Quasi-static Compression Tests}

The quasi-static compression experiments were performed on the PAM specimens at three strain rates. The true stress-strain curves are shown in Figure 5. From Figure 5, it can be seen that with the increase of compressive load, the PAM specimen has undergone the linear elastic stage, yielding stage, strian-hardening stage and failure stage, and the failure critical strain is 2.1 , showing a typical plastic failure mode. The mechanical properties parameters of the specimen under quasi-static compression are given in Table 1. From Table 1, it can be observed that as the strain rate increases, the yield stress and compressive strength (failure strength) of the specimen gradually increase, showing a significant strain rate effect. However, the elastic modulus and failure strain of the specimen remain almost unchanged, indicating that the elastic modulus and failure strain of the PAM specimen are insensitive to strain rate under quasi-static compression.

Table 1. Mechanical properties parameters of PAM sample under quasi-static compression.

\begin{tabular}{|c|c|c|c|c|}
\hline Strain rate $/ \mathrm{s}^{-1}$ & Elastic modulus /MPa & Yield stress /MPa & Compression strength /MPa & Failure strain \\
\hline 0.001 & 392.1 & 21 & 76.1 & 2.1 \\
\hline 0.01 & 394.5 & 21.5 & 78.5 & 2.1 \\
\hline 0.1 & 399.7 & 23.2 & 81.6 & 2.1 \\
\hline
\end{tabular}

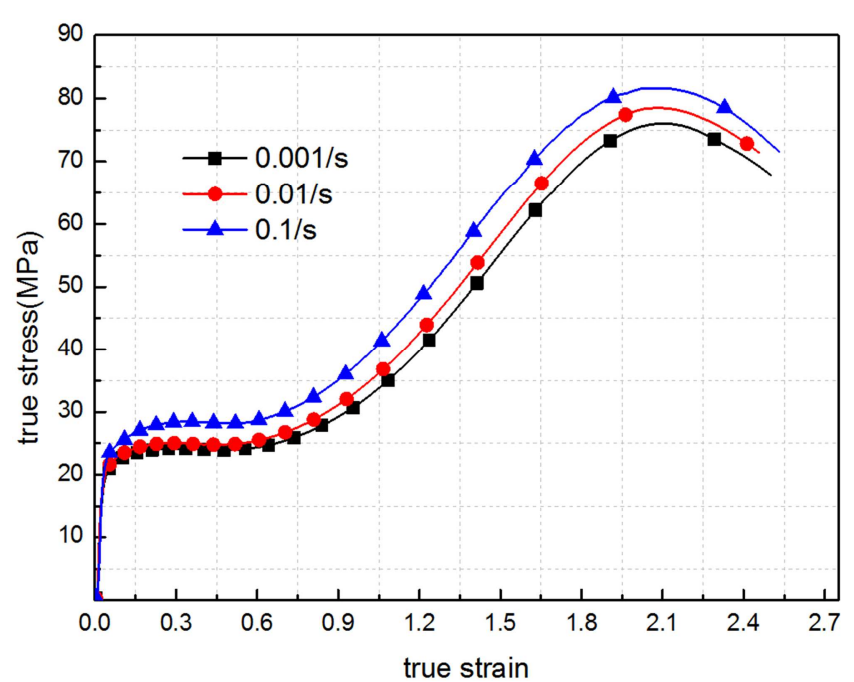

Figure 5. True stress-strain curves of PAM samples under quasi-static compression.

\subsection{SHPB Tests}

The voltage signals of the incident wave, transmitted wave, and reflected wave are extracted. The two-wave analysis method is used to calculate the dynamic stress-strain curves of the PAM specimens, as shown in Figure 6, and the corresponding dynamic mechanical performance parameters of specimens are shown in table 2. As can be seen from table 2, compared with the mechanical properties of specimens under quasi-static compression, the yield strength and compression strength of specimens under dynamic loading have been greatly improved. As the strain rate rises from $0.1 \mathrm{~s}^{-1}$ to $4000 \mathrm{~s}^{-1}$, the yield strength of PAM specimens increases from $23.2 \mathrm{MPa}$ to $50.2 \mathrm{MPa}$, and the compressive strength increases from $81.6 \mathrm{MPa}$ to $122 \mathrm{MPa}$, with an increase of $116 \%$ and $49.5 \%$, respectively. Under dynamic load conditions, the yield strength, strain-hardening modulus, compressive strength, and critical strain (corresponding to the maximum stress) of the PAM specimen increase with the increase of the strain rate, showing a significant strain rate effect.

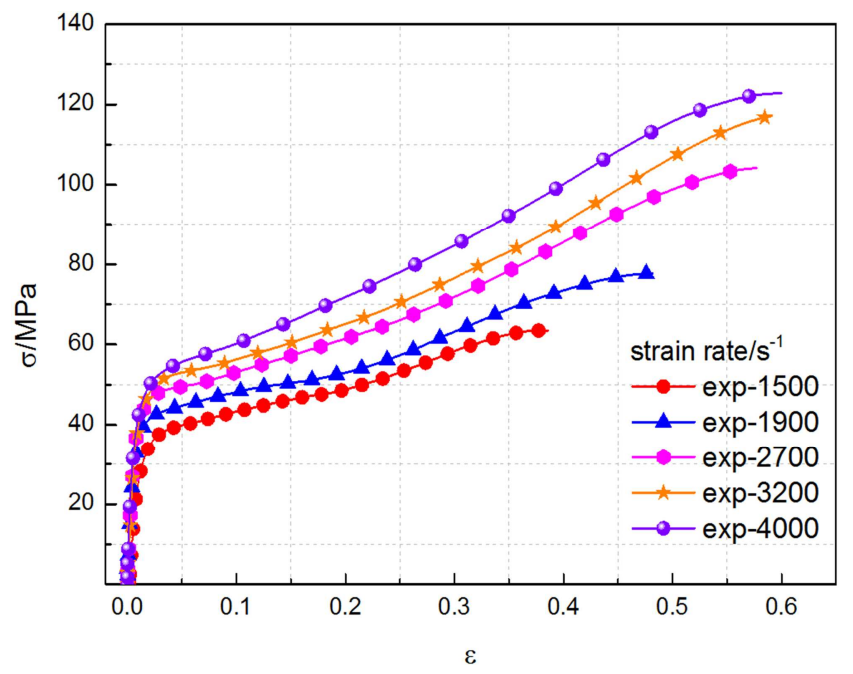

Figure 6. True stress-strain curves of PAM specimens under dynamic compression. 
Figure 7 shows the relationship between the compressive strength and the critical strain of the PAM specimen and the corresponding logarithm of the strain rate $(\ln (\dot{\varepsilon}))$. From Figure 7 , the compression strength is linearly related to the logarithm of strain rate, while the critical strain is paraboloid to the logarithm of strain rate. The compression strength $(\mathrm{MPa})$ and the critical strain equations obtained by fitting are:

$$
\sigma=60.44 \ln (\dot{\varepsilon})-375.25
$$

$$
\boldsymbol{\varepsilon}=3.96 \ln (\dot{\boldsymbol{\varepsilon}})^{2}-0.24 \ln (\dot{\boldsymbol{\varepsilon}})-15.78
$$

The correlation index $\mathrm{R}^{2}$ between the experimental value and the fitted curve is 0.97662 and 0.99573 , respectively, which is close to 1 , indicating that the experimental value is in good agreement with the fitted curve. The strain rate in equations (1) and (2) ranges from 1500 to $4000 \mathrm{~s}^{-1}$.

Table 2. Dynamic performance parameters of PAM specimens at different strain rates.

\begin{tabular}{lllll}
\hline Strain rate/ $\mathbf{s}^{-1}$ & Yield stress/MPa & Strain hardening modulus/Mpa & Compression strength/MPa & Critical strain \\
\hline 1500 & 38.3 & 75 & 66 & 0.38 \\
1900 & 41.1 & 79 & 80 & 0.48 \\
2700 & 46.2 & 104 & 104 & 0.57 \\
3200 & 121 & 117 & 0.59 \\
4000 & 48.3 & 125 & 122 & 0.60 \\
\hline
\end{tabular}

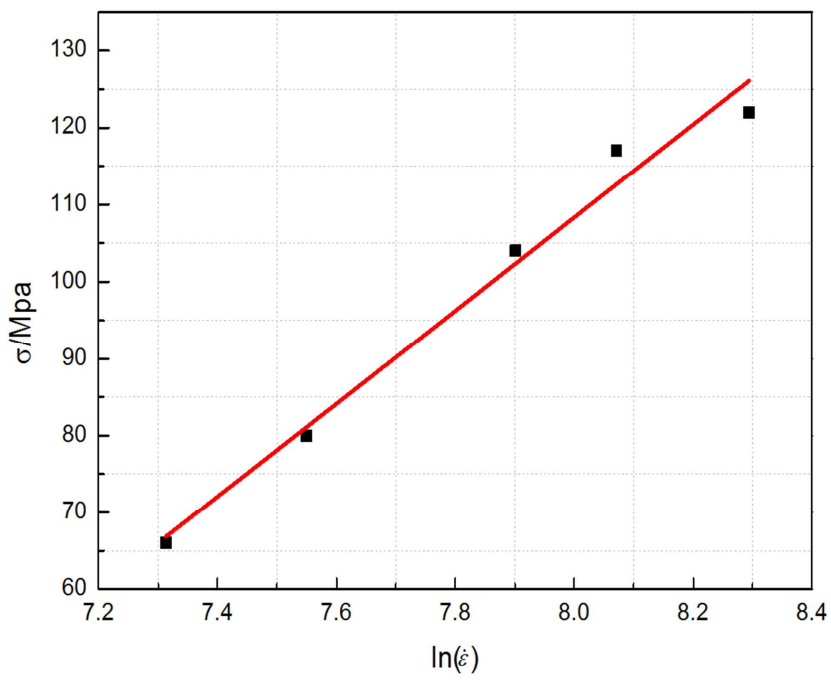

(a) compressive strength

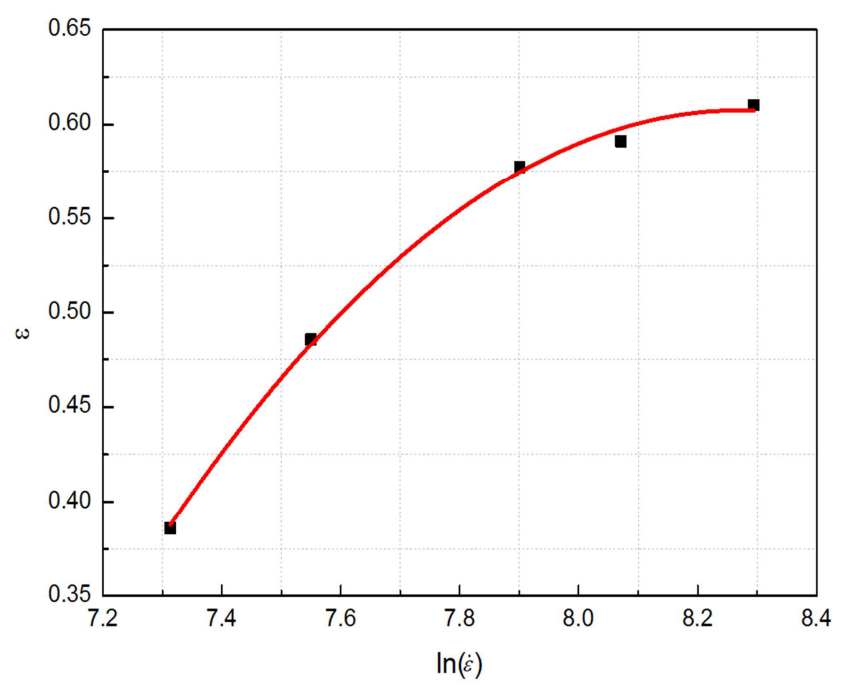

(b) critical strain

\subsection{Johnson-Cook Constitutive Model}

The Johnson-Cook (JC) model [30-31] is an empirical constitutive model that combines strain rate hardening effects, strain rate effects, and temperature softening effects. The specific form is:

$$
\boldsymbol{\sigma}=\left(\boldsymbol{A}+\boldsymbol{B} \boldsymbol{\varepsilon}_{\boldsymbol{p}}{ }^{\boldsymbol{n}}\right)\left[1+\boldsymbol{C} \ln \left(\dot{\boldsymbol{\varepsilon}} / \dot{\boldsymbol{\varepsilon}}_{0}\right)\right]\left(1-\boldsymbol{T}^{* \boldsymbol{m}}\right)
$$

Where $\sigma$ is the flow stress, $\varepsilon_{p}$ is the equivalent plastic strain, $\dot{\mathcal{E}}$ is the equivalent plastic strain rate, and $\dot{\mathcal{E}}_{0}$ is the reference strain rate, takes $1500 \mathrm{~s}^{-1}$ in this study. Since all the experiments in this study are conducted at room temperature, regardless of the temperature effect of the material, so $T^{* m}$ in this study takes 0 . A, B, C, and $\mathrm{n}$ are parameters to be determined. The relevant parameter values obtained by fitting are shown in Table 3.

Table 3. Parameters of constitutive model of PAM materials.

\begin{tabular}{lllll}
\hline & $\mathbf{A}$ & $\mathbf{B}$ & $\mathbf{n}$ & $\mathbf{C}$ \\
\hline Fitting value & 38.3 & 98.65 & 1.345 & 0.425 \\
$\mathrm{R}^{2}$ & 1.00 & 0.99028 & 0.99028 & 0.97031 \\
\hline
\end{tabular}

Therefore, the Johnson-Cook constitutive equation for the PAM material is:

$$
\boldsymbol{\sigma}=\left(38.3+98.65 \boldsymbol{\varepsilon}^{1.345}\right)\left[1+0.425 \ln \left(\dot{\boldsymbol{\varepsilon}} / \dot{\boldsymbol{\varepsilon}}_{0}\right)\right]
$$

Figure 8 shows the fitting results of a high strain rate constitutive equation for PAM materials. It can be seen from the figure that the fitting curve is in good agreement with the experimental value and only slightly deviates when the strain is close to the critical strain.

Figure 7. Relationship between dynamic compression parameters and $\ln (\dot{\varepsilon})$. 


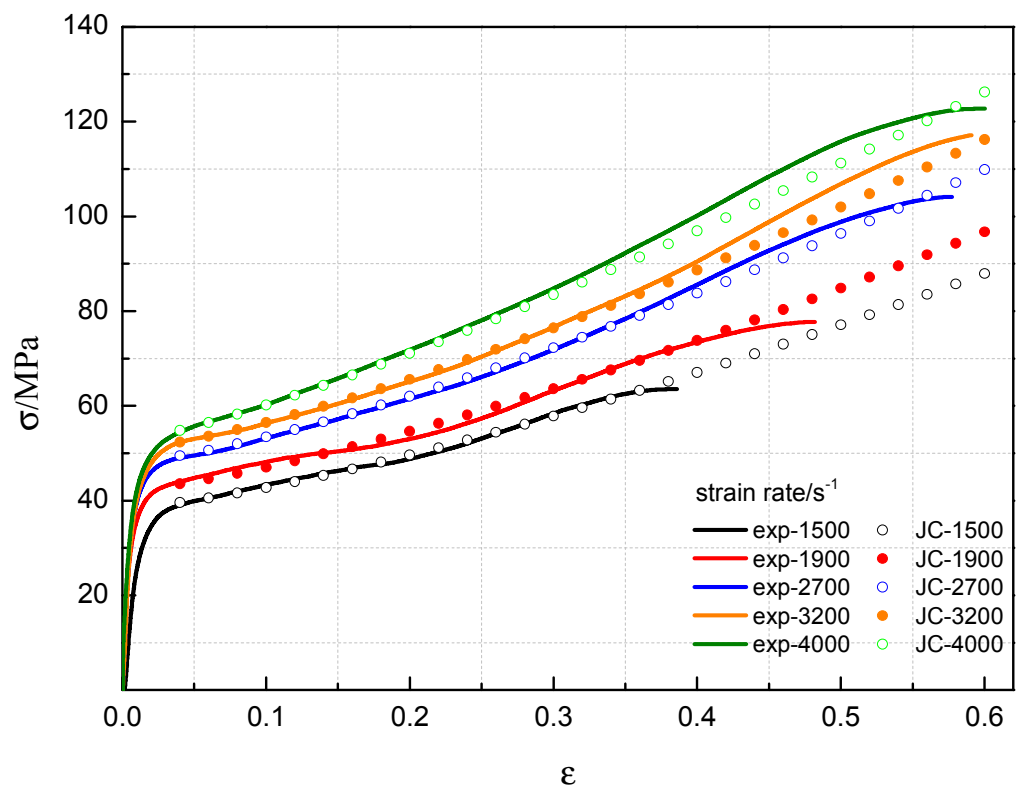

Figure 8. Fitting curves of constitutive model of PAM specimens at high strain rates.

\subsection{Drop-Weight Tests}

Figure 9 shows a sequence of images taken from high-speed camera of the PAM specimens under drop-weight tests (drop height is $1.5 \mathrm{~m}$ ). PAM specimens can react violently under the impact of a drop hammer, with intense light and a huge explosion sound. Moreover, the ignition time is about $200 \mu \mathrm{s}$ and the burning of specimen lasts approximately $800 \mu \mathrm{s}$.
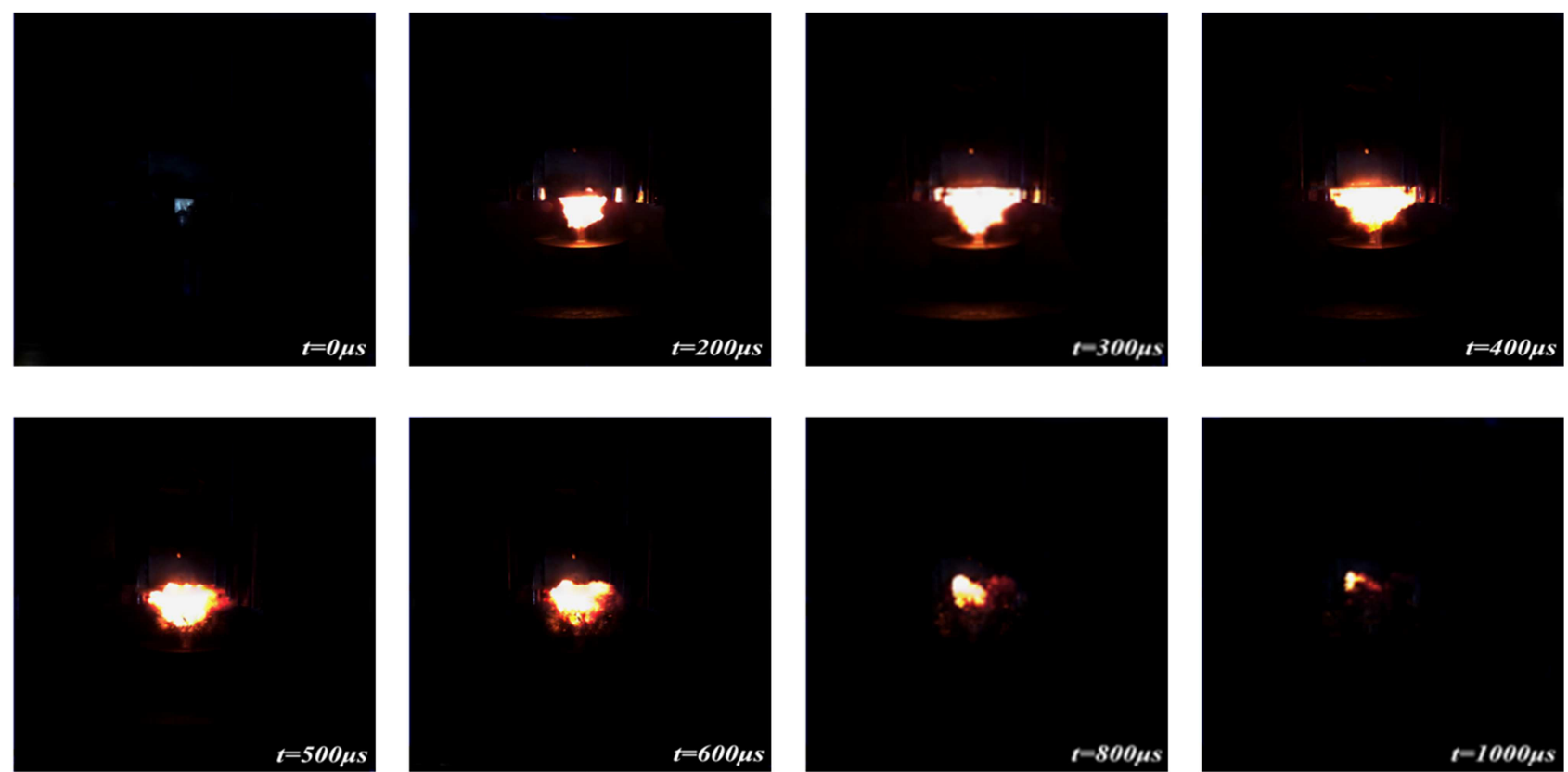

Figure 9. Reaction processes of PAM specimens under drop-weight tests.

The sensitivity of PAM specimens was measured by the characteristic drop height $\left(\mathrm{H}_{50}\right)$, when the drop mass is released from this height, the specimen has a $50 \%$ probability of ignition. H50 is calculated by the following formula:

$$
\boldsymbol{H}_{50}=\left[\boldsymbol{A}+\boldsymbol{B}\left(\frac{\sum i C_{i}}{D}-\frac{1}{2}\right)\right]
$$

Where $A$ is the lowest height in the tests, $B$ is the height increment, $D$ is the number of reaction specimens, $i$ is the order of the drop height, and $C_{i}$ is the number of reaction specimens at the specified height. The drop-weight tests were performed on 20 PAM specimens. Figure 10 shows the experimental results recorded according to the "up-and-down" methods [29]. The characteristic drop height of the PAM specimen was calculated as $58.13 \mathrm{~cm}$ according to equation (5). 


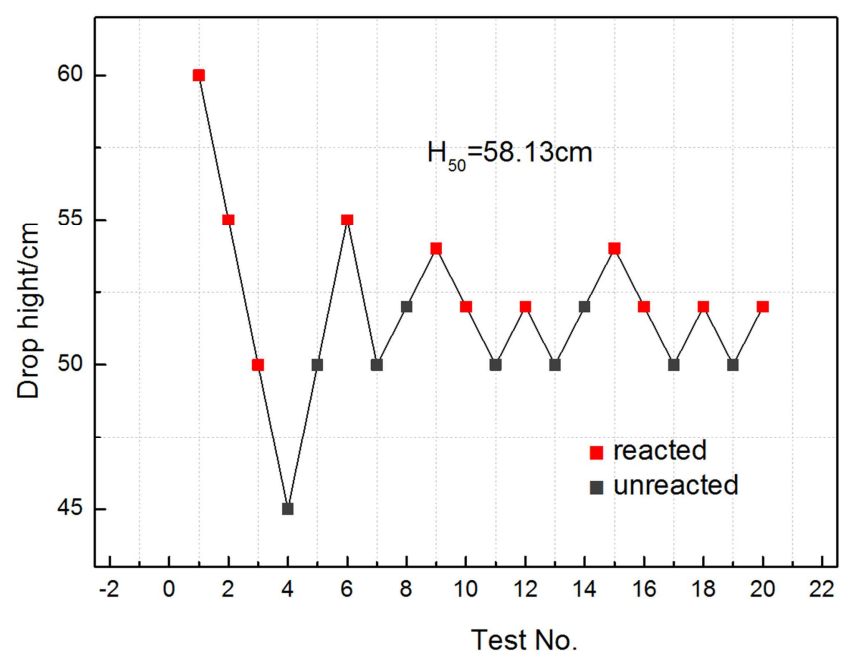

Figure 10. The drop-weight tests data points.

\section{Conclusion}

(1) Under quasi-static compression conditions, the yield strength and compressive strength of $\mathrm{PTFE} / \mathrm{Al} / \mathrm{MnO}_{2}$ specimens have obvious strain rate effects, while the elastic modulus and failure strain are insensitive to strain rate and remain almost unchanged.

(2) Under the condition of high strain rate, the yield strength and compressive strength of $\mathrm{PTFE} / \mathrm{Al} / \mathrm{MnO}_{2}$ specimens have been considerably improved. When the strain rate increases from $0.1 \mathrm{~s}^{-1}$ to $4000 \mathrm{~s}^{-1}$, The yield strength and compressive strength increased by $116 \%$ and $49.5 \%$, respectively.

(3) Under dynamic load conditions, the compressive strength of the $\mathrm{PTFE} / \mathrm{Al} / \mathrm{MnO}_{2}$ specimen has a linear relationship with the logarithm of the strain rate, while the critical strain and the logarithm of the strain rate show a parabolic relationship.

(4) The established constitutive equation can describe the mechanical behavior of PTFE/Al/ $\mathrm{MnO}_{2}$ material at high strain rate well, which can provide a reference to the practical applications of the material.

(5) PAM specimens can react violently under the impact of a drop hammer, with intense light and a huge explosion sound. And the characteristic drop height of the PAM specimen was calculated as $58.13 \mathrm{~cm}$.

\section{Acknowledgements}

The authors are very grateful for the support received from the National Natural Science Foundation of China (No. 51673213) in the experiments.

\section{References}

[1] Xie T, Jiang K, Ding Y. "Numerical simulation of influence of filler size on tribological properties of $\mathrm{Cu} / \mathrm{PTFE}$ composites". Tribology. 2016, 36 (1):35-41. (in chinese).

[2] He C X, Lu Q, Zhang J, Wan F X. "Friction and wear properties of PTFE filled with three kinds of nanostructured carbon materials". Journal of Materials Science \&Engineering. 2010 (2):186-188.

[3] Wang H X, Li Y C, Feng B, et al. "Compressive Properties of PTFE/Al/Ni Composite Under Uniaxial Loading". Journal of Materials Engineering \& Performance, 2017, 26 (5):2331-2336.

[4] Zhang J K, Wang P C, Wang L, Niu Y P, “Zhang Y Z. Tribological properties of PTFE composites filled with calcium sulphate whiskers". Lubrication Engineering. 2011, 36 (10):13-15.

[5] Feng B, Fang X, Li Y C, et al. "Reactions of Al-PTFE under impact and quasi-static compression". Advances in Materials Science \& Engineering, 2015, 2015:1-6.

[6] Xu S L, Yang S Q, "Research advance in mechanical performance of filled PTFE composite". Chemical Propellants \& Polymeric Materials. 2008, 6 (6):8-12.

[7] Zhang S J, Li Q Y, Che Y C, "Preparation and properties of composites of carbon black reinforced polytetrafluoroethylene prepared by a two-step process". Chinese Journal of Materials Research. 2016, 30 (6):427-437. (in chinese).

[8] Li C, Sun T, Shi G J, "Polytetrafluoroethylenecomposites filled with mullite and their tribological performance". Chinese Journal of Materials Research. 2016, 30 (6):427-437).

[9] Li L Q, Wu J B. "Explosive properties of the Mg-Al/PTFE composition". Chemical Intermediate. 2014 (5):30-33.

[10] Hunt E M, Malcolm S, Pantoya M L, et al. "Impact ignition of nano and micron composite energetic materials". International Journal of Impact Engineering, 2009, 36 (6):842-846.

[11] Oguni K, Ravichandran G. "Dynamic compressive behavior of unidirectional E-glass/vinylester composites". Journal of Materials Science, 2001, 36 (4):831-838.

[12] Ge C, Dong Y, Maimaitituersun W. Microscale "Simulation on mechanical properties of $\mathrm{Al} / \mathrm{PTFE}$ composite based on real microstructures". Materials, 2016, 9 (7):590.

[13] Ouk Sub Lee, Kyu Sang Cho, Sung Hyun Kim, et al. "Dynamic deformation behavior of soft material using SHPB technique and pulse shaper". International Journal of Modern Physics B, 2006, 20 (25): 3571-3576.

[14] Hsiao HM, Daniel IM, Cordes RD. "Dynamic compressive behavior of thick composite materials". Experimental Mechanics 1998; 38:172-80.

[15] Hsiao HM, Daniel IM, Cordes RD. "Strain rate effects on the transverse compressive and shear behavior of unidirectional composites". Journal of Composite Materials 1999; 33: 1620-42.

[16] Wu J X, Fang X, Gao Z R, et al. "Investigation on mechanical properties and reaction characteristics of Al-PTFE composites with different Al particle size". Advances in Materials Science \& Engineering, 2018, 2018 (7):1-10.

[17] Feng B, Fang X, Li Y C, et al. "An initiation phenomenon of Al-PTFE under quasi-static compression". Chemical Physics Letters, 2015, 637:38-41.

[18] Feng B, Li Y C, Wu S Z, et al. "A crack-induced initiation mechanism of Al-PTFE under quasi-static compression and the investigation of influencing factors". Materials \& Design, 2016, 108:411-417. 
[19] Feng B, Fang X, Wang H X, et al. "The effect of crystallinity on compressive properties of Al-PTFE". Polymers, 2016, 8 (10):356 .

[20] Xu F Y, Liu S B, Zheng Y F, et al. "Quasi-static compression properties and failure of $\mathrm{PTFE} / \mathrm{Al} / \mathrm{W}$ reactive materials". Advanced Engineering Materials, 2017, 19 (1).

[21] Ge C, Maimaitituersun W, Dong Y, et al. "A study on the mechanical properties and impact-induced initiation characteristics of brittle $\mathrm{PTFE} / \mathrm{Al} / \mathrm{W}$ reactive materials". Materials, 2017, 10 (5).

[22] Wang L, Liu J, Li S, Zhang X. "Insensitive high-energy energetic structural material of tungsten-polytetrafluoroethylene-aluminum composites". Aip Advances, 2015, 5 (11):169-174.

[23] Zhou J, He Y, He Y, et al. "Quasi-static compression properties and impact energy release characteristics of Al/PTFE/W reactive materials". Chinese Journal of Energetic Materials. 2017, 25 (11):903-912. (in chinese).

[24] Ren H L, Liu X J, Chen Z Y. "Reaction behavior of A1/PTFE materials enhanced by W particles". Acta Armamentarii. 2716, 37 (5):872-878. (in chinese).

[25] Huang J Y, Fang X, Li Y C, et al. "The mechanical and reaction behavior of PTFE/Al/ $/ \mathrm{Fe}_{2} \mathrm{O}_{3}$ under impact and quasi-static compression". Advances in Materials Science and Engineering, 2017, 1-9.
[26] Tao Z M, Fang X, LI Y C, et al. "Preparation and performances of reactive $\mathrm{Al} / \mathrm{Fe}_{2} \mathrm{O}_{3} / \mathrm{PTFE}$ material". Chinese Journal of Energetic Materials. 2016, 24 (8):781-786. (in chinese).

[27] Hopkinson B. "A Method of measuring the pressure produced in the detonation of high explosives or by the impact of bullets". Philosophical Transactions of the Royal Society of London, 1914,213 (612):437-456.

[28] Kolsky H. "An investigation of the mechanical properties of materials at very high rates of loading". Proceedings of the Physical Society B, 1949, 62 (11):676.

[29] Blackstone, W. R.; Baber, B. B.; Ku, P. M. "New test techniques for evaluating the compatibility of materials with liquid oxygen under impact". ASLE Transactions, 1968, 11 (3):216-227.

[30] Johnson, G. R., Cook, W. H. "A constitutive model and data for metals subjected to large strains, high strain rates, and high temperatures" Proceedings from the 7th International Symposium on Ballistics, 1983: 541-547.

[31] T. J. Holmquist, G. R. Johnson. "Determination of constants and comparison of results for various constitutive models". Journal de Physique Iv, 1991, IV 1 (C3):299-306. 